\title{
Assessing Brunei Darussalam Public and Private Sector Readiness Towards Big Data Application
}

\author{
Muhammad Azmi Sait, Universiti Brunei Darussalam, Brunei \\ (iD https://orcid.org/0000-0002-5175-6436 \\ Muhammad Anshari Ali, Universiti Brunei Darussalam, Brunei \\ iD https://orcid.org/0000-0002-8160-6682
}

\begin{abstract}
This exploratory study aims to assess and investigate Brunei Darussalam's readiness in developing and applying big data technologies for its public and private sectors, using the social, technological, environmental, and policy (STEP) framework. The results show that the population are digitally literate (social) and utilise smart devices as well as internet network connectivity that is widely offered by the local telecommunications company (technology). The government of Brunei Darussalam established multiple digital transformation initiatives including implementation of $5 \mathrm{G}$ connectivity as well as digital economy masterplan to digitally transformed in the near future (environment). Regardless of the absence of national digital data privacy policy (policy) in Brunei, the recent nation's successful big data application in public sector-BruHealth Application-to contain COVID-19 community spread was achieved. The existence of such policy in the near future will create opportunities for the local private sectors to capitalise on big data technologies to their business strategies.
\end{abstract}

\section{KEYWORDS}

ASEAN, Big Data, Brunei Darussalam, Digital Readiness, Private Sector, Public Sector

\section{INTRODUCTION}

Brunei Darussalam is a monarch country blessed with a stable geopolitical environment under the ruling of the Sultan who is the monarchical head of state of the government and also the Prime Minister of Brunei Darussalam. Recently, Brunei Darussalam has been associated with economic issues rooting from its high dependency on its oil and gas industry that has been sensitive to the low market demands (reflected by the low oil prices) since its price plunge in 2014 from rise of "US shale oil" (Stocker et al., 2018). Thus, there has been efforts to diversify Brunei Darussalam's economy towards value added manufacturing and services industry. The product and services niches that Brunei Darussalam has been venturing into includes halal industry (including food and beverages, cosmetics and pharmaceuticals), tourism (through Brunei Darussalam's Bio-Innovation Corridor

DOI: 10.4018/IJABIM.20220701.oa7

This article published as an Open Access article distributed under the terms of the Creative Commons Attribution License (http://creativecommons.org/licenses/by/4.0/) which permits unrestricted use, distribution, and production in any medium, provided the author of the original work and original publication source are properly credited. 
- BIC launched in early 2014) and petrochemical industry (Ain Bandial \& Rasidah Hj Abu Bakar, 2019). Inherently, Brunei Darussalam may lose in terms of scale, for its local market population is only 459,500 (DEPS, 2019). However, being strategically positioned on North-West of Borneo Island, Brunei Darussalam would have the opportunity to capture a larger market segment of approximately 16 million people (Borneo Project, 2014).

In the recent Titah by His Majesty the Sultan, he has emphasised the relevance of moving towards big data applications for its public and private sectors, in order to capitalise the market trends of the neighbouring countries to enhance the marketability of the aforementioned product and service niches (Azlan Othman, 2020). Moving in parallel to current global technological advancement, His Majesty has addressed the establishment of a five-year roadmap of Digital Economy Masterplan 2025 that entails 17 projects that aims to transform Brunei Darussalam into a "Smart Nation". Implementing big data application (complemented with technologies related to it i.e. big data analytics, artificial intelligence, machine learnings) to the current Brunei Darussalam economy would have the potential to boost up our efficiency in terms of governance and businesses as it carries the benefit of gaining better understanding of the vast amount of opportunities to aide the key stakeholders from public and private sector in making a better judgement and decision concisely (G.-H. Kim et al., 2014; Wamba et al., 2015).

The purpose of this paper is to assess Brunei Darussalam readiness in the aspects of social, environmental, technological, policy and regulatory (STEP) frameworks in allowing conducive conditions for developing and implementing big data technologies for its public and private sectors. The objectives of this research are to evaluate Brunei Darussalam's current readiness in implementing big data technologies based on the current available social capability, technologies, environment and policy and regulatory frameworks through interviews with relevant stakeholders; to identify the current on-going big data application related project(s) in Brunei Darussalam as well as the challenges being faced by the project stakeholders on the aforementioned projects; and lastly acts as initial guidelines for policy makers in creating relevant policies with regards to data governances for the future big data applications in Brunei Darussalam's public and private sectors. The rest of this paper is organised as follows: next section will cover on the literature reviews on topics that are deemed relevant in understanding the concept of big data, its applications in public and private sectors as well as examples that of Asia-region countries that utilises it and key enablers to big data applications (STEP). Next will cover on the methodology that was deployed to reach the aim and objectives of this paper. Then the next section will present and discuss the quantitative and qualitative results that was collected from primary and secondary data sources. Final section will cover the conclusion of this paper.

\section{LITERATURE REVIEW}

\section{Big Data Application in Public Sector}

Public sector is part of the nation's economy that consisted of "governments and all publicly controlled or publicly funded agencies, enterprises and other entities that deliver public programs, goods or services" (Dube \& Danescu, 2011). There are three types of organisations within the public sector: core government, agencies and public enterprises; and two types of organisations that are within the grey zone (may or may not be) as part of the public sector. Core government is the governing bodies that have well defined authorities that includes the departments and ministries that are within the government which will report directly to the central authorities such as the council, cabinets or legislatures. Agencies are governmental bodies that exists as separate organisations that delivers public services, goods and programs, for example, public hospitals and health care institutes. Public enterprises are government agencies that operates independently and often have their own sources of revenues in addition to direct public finding, to deliver public program, goods or services, such local public universities for example University Brunei Darussalam (UBD). 


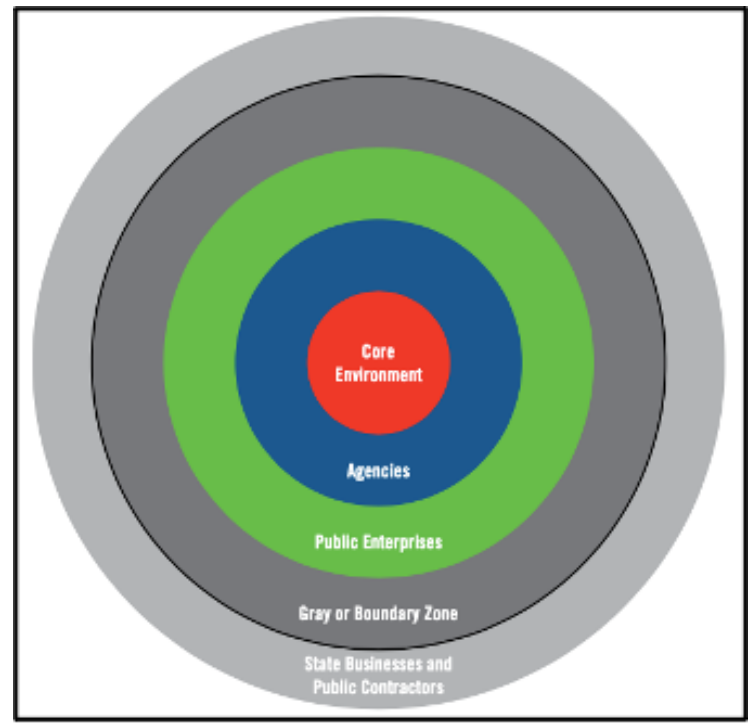

Big data applications in public sector has the potential to increase the operational effectiveness between the said core government bodies, agencies and public enterprises. Moreover, big data analytics within public sectors would promote transparencies and cooperativeness between the key players by the sharing of vast amount of diversified data from multiple sources within the governmental bodies which enable the decision making processes to be more fluent and effectual in the long run (G.-H. Kim et al., 2014). Traditionally, decision making processes in public sectors took a very long period of time because it is carried out through multiple consultations and mutual approvals from diversified key players.

Big data applications have been seen to be used within the major key parts of the public sector domains such as health care systems (Gaitanou et al., 2014; Galetsi et al., 2019; Raja et al., 2020), law and enforcements (Rajagopalan \& Vellaipandiyan, 2013; Saxby \& Knight, 2013) and education systems (Gunness \& Singh, 2015; Y. H. Kim \& Ahn, 2016; Peterson, 2018). Primarily, according to Kim et al. (2014), the aforementioned key public sectors use big data as the tool to aid in, "predictive analytics, enhance transparency, increase citizen engagement in public affairs, improve national security and support wellbeing of people through better education and healthcare."

\section{Big Data Application in Private Sector}

Since the early days of digital technologies (the essence of interconnectivity within the global networks), the key players or stakeholders in business industries i.e. entrepreneurs, executives, investors, business over-watchers, have been observing its high potential of in capturing the segment of customers and consumers through the interconnectivity of people. Utilisation of such technology would give competitive edge for companies that deploys it in terms of increasing their operational effectiveness and strategic positioning compared to companies that excludes it in their strategy (Porter $\&$ Gibbs, 2001). In gaining competitive advantages in the business markets, firms and companies have few actions that they deploy, that can be perceived as common trend within any company's strategies. Thompson et al (2013) stated that companies common actions and approaches in making their strategy is as being illustrated in the figure below.

Based on this figure, it can be seen that the sole mission of businesses is to capture significant part of the business market by strengthening their competitive position over other business firms via 
Research \& Development (R\&D) departments which consequently satisfy their customers by catering quality directly to their known demands (G.-H. Kim et al., 2014). Moreover, the figure also shows the potential of business growth through predicting and monopolising the new emerging market opportunities before the market becomes saturated. This majorly requires the decision maker to make decisions promptly and accordingly with utmost confidence to ensure the success of their strategy. This is where big data applications is the most relevant to be used.

The concept of big data applications has become significant in the business world (private sectors) because it is believed to have high potential in facilitating a better well rounded short term decision makings and strategies by utilizing automated algorithms (Ohata \& Kumar, 2012; Tankard, 2012; White, 2012); permitting innovations to create new business models, products and services (Ohata \& Kumar, 2012; Tankard, 2012); enables customization of actions that caters directly to the demands and needs of a segmented populations (Demirkan \& Delen, 2013; Griffin, 2012); obtaining up-to-date factual information of their consumers (Chang, 2018); thus optimizing the operationality and profitability (Anderson \& Blanke, 2012) of certain business' product niche which would help in sustaining their operational effectiveness and competitive advantage over other business firms. In an essence, big data has evolved business intelligence (BI) in the utilization of IT-enabled decision support systems - from aiding businesses in reporting their sales performances and as decision support - into giving an advantage in predicting the next big thing and better short-term decision making (G.-H. Kim et al., 2014).

\section{STEP Framework (Key Enablers to Big Data Application)}

There are multiple factors that contributes to the adoption of new technologies within any country. In the context of big data technologies, it may range from the digital literacy, availability of high-speed data interconnectivity, broad adoption of digital devices as well as existence of data governance

Figure 2. Identification of a Company's Strategy adopted from Thompson et al (2013)

\begin{tabular}{|c|c|c|}
\hline $\begin{array}{l}\text { Actions to stre } \\
\text { firm's bargain } \\
\text { with suppliers } \\
\text { and others }\end{array}$ & \multicolumn{2}{|c|}{$\begin{array}{l}\text { Actions to gain sales and market share via more } \\
\text { performance features, more appealing design, better } \\
\text { quality or customer service, wider product selection, } \\
\text { or other such actions }\end{array}$} \\
\hline $\begin{array}{l}\text { Actions to upgrade, } \\
\text { build, or acquire } \\
\text { competitively important } \\
\text { resources and } \\
\text { capabilities }\end{array}$ & & $\begin{array}{l}\text { Actions to gain sales and } \\
\text { market share with lower } \\
\text { prices based on lower } \\
\text { costs }\end{array}$ \\
\hline $\begin{array}{l}\text { Actions and approaches } \\
\text { used in managing } \\
\text { R\&D, production, } \\
\text { sales and marketing, } \\
\text { finance, and other } \\
\text { key activities }\end{array}$ & $\begin{array}{l}\text { ONS AND } \\
\text { IPPROACHES } \\
\text { JEFINE A } \\
\text { PANY'S } \\
\text { ITEGY }\end{array}$ & $\begin{array}{l}\text { Actions to enter new } \\
\text { product or geographic } \\
\text { markets or to exit } \\
\text { existing ones }\end{array}$ \\
\hline $\begin{array}{l}\text { Actions to strengthen } \\
\text { competitiveness via strategic } \\
\text { alliances and collaborative } \\
\text { partnerships }\end{array}$ & $\begin{array}{l}\text { engthen market } \\
\text { competitiveness } \\
\text { or merging } \\
\text { npanies }\end{array}$ & $\begin{array}{l}\text { ons to capture emerging } \\
\text { ket opportunities and } \\
\text { and against external } \\
\text { ats to the company's } \\
\text { iness prospects }\end{array}$ \\
\hline
\end{tabular}


Table 1. Attributes of Public and Private Sectors adopted from Kim et al. (2014)

\begin{tabular}{|l|l|l|}
\hline \multicolumn{1}{|c|}{ Attribute } & \multicolumn{1}{c|}{ Public Sectors } & \multicolumn{1}{c|}{ Private Sectors } \\
\hline Goal & Domestic tranquillity, sustainable development & Profit to stakeholders \\
\hline Mission & $\begin{array}{l}\text { Security of basic rights, promoting public } \\
\text { welfare, economic growth }\end{array}$ & $\begin{array}{l}\text { Development of competitive edge, } \\
\text { customer satisfaction }\end{array}$ \\
\hline Decision Making & $\begin{array}{l}\text { Long-term decision-making to maximise self- } \\
\text { interest and promote public interest }\end{array}$ & $\begin{array}{l}\text { Short-term decision-making to } \\
\text { maximise self-interest and minimise } \\
\text { cost }\end{array}$ \\
\hline Decision Actors & Diverse decision actors & Limited number of decision actors \\
\hline Organisational Structure & Governance & Hierarchical \\
\hline Financial Resources & Taxes & Revenue \\
\hline $\begin{array}{l}\text { Nature of Collective } \\
\text { Activity }\end{array}$ & Cooperation and Checking & Competition and engagement \\
\hline
\end{tabular}

in the form of data privacy and policy. These aforementioned factors can be put under generalised themes (STEP) such as: Social, Technological, Environmental as well as availability of data Policy. The following sections will explore more on the topics relevant to each theme.

\section{Social and Environmental Aspect}

Social and Environmental factors in this context refers to the societal capacity in the aspect of possessing adequate knowledge, skills, literacies and proficiencies to enhance developmental growth (Putterman, 2013) as well as environmental influences that pressures the society to adapt in this technological era (Reddy et al., 2020). These attributes are usually obtained through education, trainings and experience, among others. In this research paper, to be consistent with the theme of big data's technological adoption, this section will be associated with intellectuality, digital literacy and competitive environment which can be quantitatively measured through human development index (HDI) and Global Competitive Index (GCI) of the nations of interest respectively. HDI would mainly measure the microscale of social capability based on populations' life expectancy, level of education and purchasing power. On the other hand, GCI would measure the competitiveness of both macro and microeconomic aspects of nation into single index. Nations with high HDI and GCI are believed to have the ideal condition towards successful implementation of new technologies and thus have the potential to be the hub for future innovations.

\section{Human Development Index (HDI)}

Prior to obtaining digital literacy (and intellectuality), conducive macroscale environment that heavily contributes to basic imperative knowledge, skills and proficiencies of the society needs

\section{Table 2. Key enablers to big data applications}

\begin{tabular}{|l|l|}
\hline \multicolumn{1}{|c|}{ Key Enabler } & \multicolumn{1}{c|}{ Description } \\
\hline Social & The societal capacity of possessing digital knowledge, skills, literacies and proficiencies \\
\hline Technology & $\begin{array}{l}\text { The availability of relevant digital technologies i.e. smart devices, network connectivity, for } \\
\text { the society }\end{array}$ \\
\hline Environmental & The environmental influences that pressures the society to adapt digital transformation \\
\hline Policy & The policy that governs the digital data security and policy of the society \\
\hline
\end{tabular}




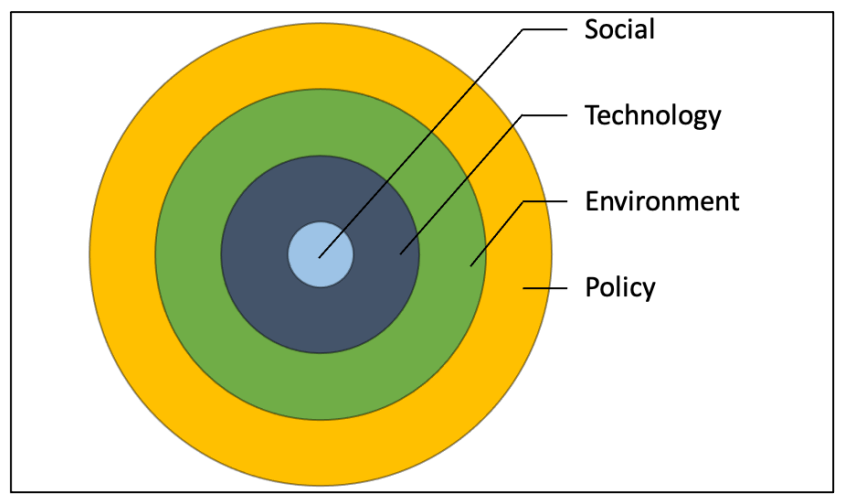

to be present. This can be assessed through the Human Development Index (HDI). According to (Conceição, 2019), HDI refers to an average statistical measurement of a country's achievements in the aspect of human development such as its people's health, level of education attainment and standard of living.

According to Spires et al. (2019), digital literacy refers to the quantity of digital reading and writing techniques that individuals are able to perform "across multiple media forms including words, texts, visual displays, motion graphics, audio, video and multimodal forms." In addition to that, researchers also incorporates digital literacy with cognitive ability, thus added the notion that digital literacy is also associated with the capacity to use critical thinking skills to apprehend and utilise information in multiple digitalised formats in contrast to only creating, viewing and reading the said data (Chan et al., 2017).

Moreover, digital literacy can be divided into three categories that comprises of various intellectual processes associated with it such as "locating and consuming digital content, creating digital content and communicating digital content" (Spires \& Bartlett, 2012). Based on the aforementioned statement, society with high digital literacy are believed to heavily incorporate digital devices to perform their day-to-day tasks efficiently and effectively thus would be the best candidate of massive and richer data source, thus satisfies the first fundamental characteristics of big data technology. With this idea in mind, it would signify that the degree of societal digital literacy corresponds to the amount of data produced.

In HDI's three categories, the health aspect (people's health) is measured by the populations' life expectancy. The educational aspect (level of education attainment) is measured by the average years among adults aged 25 and above as well as the expected number of years for children of school entering age. Finally, the aspect of standard of living is measured by the populations' gross national income (GNI) per capita (2011 PPP\$ - purchasing power proprietary) that would inherently correspond to the population's purchasing power. Purchasing power would measure the amount of disposable incomes of the country's population thus their ability to acquire necessities to survive in this digitally driven era.

\section{Global Competitiveness Index (GCl)}

Global Competitiveness Index (GCI) as is being mentioned earlier, measures the factors that significantly contributes to the degree of competitiveness and conduciveness of nation's environments to drive innovations and technological development. Higher competitivity would significantly drive the innovation within the said society. 
Table 3. List of NRI sub-pillars used in this research paper

\begin{tabular}{|l|l|l|l|}
\hline \multicolumn{1}{|c|}{ Categories } & \multicolumn{1}{|c|}{ Pillars } & \multicolumn{1}{c|}{ Code } & \multicolumn{1}{c|}{ Sub-Pillar Used } \\
\hline \multirow{2}{*}{ Enabling Environment } & \multirow{2}{*}{ Institutions } & 1.12 & E-Participation \\
\cline { 3 - 4 } & & 1.23 & Government Long-term vision \\
\hline \multirow{3}{*}{ Human Capital } & \multirow{2}{*}{ Skills } & 6.02 & Extent of staff training \\
\cline { 3 - 4 } & & 6.05 & Digital skills among active population \\
\hline \multirow{3}{*}{ Markets } & Product Market & 7.03 & Competition in services \\
\hline \multirow{3}{*}{ Innovation Ecosystem } & \multirow{2}{*}{ Business Dynamism } & 11.07 & Growth of innovative companies \\
\cline { 2 - 4 } & & 11.08 & Companies embracing disruptive ideas \\
\cline { 3 - 4 } & \multirow{3}{*}{ Innovation Capability } & 12.03 & International co-inventions \\
\cline { 3 - 4 } & & 12.05 & Scientific publications \\
\cline { 3 - 4 } & & 12.06 & Patent applications \\
\cline { 3 - 4 } & & 12.07 & R\&D expenditures \\
\cline { 3 - 4 } & & 12.08 & Research institutions prominence \\
\hline
\end{tabular}

\section{Technological Aspect}

Next, technological availability in this research paper refers to the availability as well as ease of access to such technologies on a nation's micro and macro level, that are deemed as the basic requirement and necessities to big data technologies. The main technologies that will be covered in this paper revolves around the four characteristics of big data which are volume and value (i.e. cloud computing infrastructure), variety (i.e. Internet of Things) and velocity (i.e. 5G network). These aforementioned technologies that will be the basis for big data applications will be discussed in the following sections.

\section{Cloud Computing With Integrated Analytics}

Cloud computing is not a new notion in the information and computing technology (ICT) world. In fact, as far back as the 1960s, cloud computing - previously known as Utility Computing - has been a focus of development to researchers such as Douglas Parkhill and John McCarthy, with the aim to "provide users with services via the Internet" for utilities that are traditionally available such as water, gas and electricity (Durao et al., 2014). Nowadays, cloud computing is aimed to deliver all the functionalities of high-end computing capability and high volume of storages that suits the endusers through the Internet without the need to incur large capital to obtain such physical hardware.

Cloud computing, as defined by Marston et al. (2011), is "an information technology service model where computing services (both hardware and software) are delivered on-demand to customers over a network in a self-service fashion, independent of device and location. The resources required to provide the requisite quality-of-service levels are shared, dynamically scalable, rapidly provisioned, virtualised and released with minimal service provider interaction. Users pay for the service as an operating expense without incurring any significant initial capital expenditure, with the cloud services employing a metering system that divides the computing resource in appropriate blocks." This statement entails the idea that the users of cloud computing systems do not require any specialised devices, as the computing capability can be conveniently accessed by the users from the cloud providers. However, it needed the availability of internet network and the digitally literate users to utilise the capability of cloud computing infrastructures to the full advantage.

Due to the main strength of cloud computing of not needing to obtain such expensive computer hardware, it has gained utmost interests to SMEs and people in general. Cloud computing has inherently lowers the entry barrier for SMEs to participate in market segments that was previously 
dominated by large enterprises that has more than enough capitals to benefit from computer-intensive business analytics that requires super-computers (Marston et al., 2011). There are three known cloud computing delivery model architectures: Software as a Service (SaaS), Platform as a Service (PaaS) and Infrastructure as a Service (IaaS) (Marston et al., 2011).

These three models have different objectives at hand. SaaS is used to run applications on cloud by removing the need to install such software on personal devices i.e. Google's Gmail, G-Docs, G-Sheet and G-Slides; PaaS is used mainly for application developers that do not have adequate capital to invest in hardware and software i.e. Google App Engine, Amazon Relational Database Service and Rackspace Cloud Sites; and lastly, IaaS is mainly used as storage for those who needs it i.e. Google Drive, Dropbox, Amazon S3 Storage Services.

Moreover, there are four types of cloud infrastructures that can be found today which includes: public cloud, private cloud, community cloud and hybrid cloud (mixture of public and private cloud). Public cloud is available to public via internet; private cloud is only for intranet infrastructure, usually to store government confidential data; community cloud is also only available through intranet infrastructure between organisations with the same common goals; hybrid cloud where non-essential data are available to public via internet and critical data are enclosed via intranet such that in the case of e-government services where public can access only restricted data whilst authorities have full access to all data within such cloud (Durao et al., 2014).

Evidently, based on the aforementioned infrastructure and architectures of cloud computing models, it can be concluded that the providers of such clouds are able to collect vast amount of multi-dimensional data be it structured and unstructured. For example, a big data application for private sectors in South Korea, a hybrid PaaS cloud, dubbed "KT Cloud" reportedly has at least 113 Terabytes of data storage containing structured and unstructured data ranging from consumers' buying behaviours to the local delivery routes, integrated with AI algorithm for data analytics to draw out valuable information from such vast amount of data by the end-users (Ku, $\mathrm{K}$ et al. 2014). This has shown the utmost potential of cloud computing that would be a necessity for any country's public and private sectors that wanted to venture into this cutting-edge big data application.

\section{Internet of Things With Fast Network Connectivity}

Internet of things (IoT), or interconnectivity of devices, implies the paradigm shift, from individually isolated conventional devices usability in the past, towards the emergence of smart devices that are integrated with sensors and processing technologies capable of communicating and exchanging enduser information with other smart devices network (D2D i.e. device-to-device or M2M i.e. machineto-machine interaction) via wireless connectivity (Asghari et al., 2019; Bello \& Zeadally, 2019; Fortino et al., 2017; Souri et al., 2019). The widespread availability of interconnected smart devices (IoT-enabled devices) have been extensively utilised in homes, road safety practices, educational institutes, factories, agricultural environments and health care centres, among others (Gubbi et al., 2013; T. Kim et al., 2017; Muralidharan et al., 2018; Terroso-Saenz et al., 2019), with the common aim to improve the quality of end-user experiences which in turn enhances the quality of service (QoS) as a whole.

IoT smart devices may be in the form of smart televisions, smart phones, smart fridges, smart CCTV, smart watches, to name a few. In addition to that, Mistry et al. (2020) have denoted that IoT-enabled applications will positively influence road travel experiences and health monitoring procedures thus increasing the effectiveness of government and public authorities in reducing the cost incorporated within the domains of road safety and healthcare costs. Enabling technologies that becomes the basis for IoT infrastructures are cloud computing system as well as network connectivity. In brief, cloud computing contributes as the main data collection bucket by providing a centralised data storage system that features efficient storage and processing techniques to collect enormous amount of data generated from the interconnected smart devices (Mistry et al., 2020). 
Another crucial technology to enable connectivity between the smart devices is "a secure, compatible, reliable and expandable network connectivity" (Aheleroff et al., 2020) in the form of wireless open channel connection such as "sensor networks, radio frequency identification (RFID), near field communication (NFC) and Bluetooth" (Shah \& Yaqoob, 2016). As being mentioned earlier, the data transmissions between IoT devices will be enormous, thus, there is the need for the network connectivity that possess high bandwidth with improved data-rate as well as low latencies in addition to high security (Khurpade et al., 2018). Such network configuration can only be achieved by the new $5 \mathrm{G}$ network connection, which is deemed as the key enabler to IoT-enabled applications (Mistry et al., 2020).

Its main feature of Massive-Input Massive-Output (MIMO) illustrates its capability to operate at higher frequency (between $30 \mathrm{GHz}$ to $300 \mathrm{GHz}$ ) thus incorporates "higher data rates, reduced latencies, lower energy requirements and higher scalability" as it has more condensed network infrastructure in contrast to 4G LTE configurations (Mistry et al., 2020). This "snappy" connectivity will inherently support the concept of real-time data collection from IoT-enabled devices to the users and provide value-added information whilst maintaining low overall cost in this era of data-driven approach services (Aheleroff et al., 2020). Finally, as mentioned by Pervez et al. (2018), the key advantages that IoT will contribute to the current way of life are as below:

- Full automation and control over the smart devices operation;

- Able to perform full-time monitoring which may not be possible to be performed by humans;

- Optimal usage of resources (e.g. time, money, energy, electricity) by eliminating the human needs to do work i.e. optimal environment, wages, etc.;

- Creating valuable information by accessing the collected data;

- Ability to efficiently intervene when there are problems at hand;

- Effectively aide in decision makings as accurate results can be swiftly obtained;

- Improve Quality of Service (QoS) by optimising the service management completely;

- All in all, this section exhibits the importance of IoT with 5G enabled network connectivity in satisfying the last two characteristics of big data i.e. velocity and variety.

\section{Policy Aspect}

Data, information and ideas exists in the form of abstract. This type of abstract material is non-rival that can be shared with other entities without losing any of its content. Unlike rival materials such as water, only its consumers have the privilege of consuming it whilst others don't (Duch-Brown et al., 2017). Thus, the problem that becomes more apparent in this digital era is data privacy. Drawing the line between creating valuable information collected from the enormous multidimensional types of personalised data (i.e. patient's health information, daily GPS locations, or facial recognitions) and ensuring the people's rights to their privacy has been a popular discussion within the academia. These types of data may contain sensitive information that can be directly linked to the individuals from which it was collected (Nelson \& Olovsson, 2016). One of the main reasons to this discomforting situation is because the users of the big data (i.e. business owners) sees it as having utmost potential to understand their environment but the data owners (i.e. customers, consumers, buyers) may perceive it as privacy breach. Thus, privacy policy needs to be established to ensure the society as a whole has the utmost confidence to share their data to the authorities that governs the big data collection.

\section{METHODOLOGY}

The type of research conducted in this study is an exploratory research in which its essence is to discover occurrences or phenomenon that is relatively new or unknown in the past and in turn would reveal results that are worthy for future researches (Swedberg, 2018). This research paper aims to assess 
and investigate Brunei Darussalam's readiness in implementing big data applications for its public and private sectors as well as its potential contributions to the sectors' performances and productivity.

Considering the relatively new notion of big data technologies and its applications concept in developing countries such as Brunei Darussalam and taking into account its increasing relevancy in this era of digitisation, research papers similar to this study might still be very limited. Thus, it is hoped that this research paper will contribute in filling the existing knowledge gap in this field.

\section{Sampling Selection}

In the attempt to achieve the aim and objective of this research, a purposive sampling method (i.e. a non-probability sampling method where respondents or interviewees are recruited based on the judgement of researchers) is deployed. More specifically, interviewees that the researcher believe to have relevant knowledge and experiences in relation to the field being studied are chosen as the source of information in this research paper. In the case of this research, the chosen interviewees are the representatives from Authority for Info-Communications Technology Industry (primary data), Minister at Ministry of Health and Ministry of Finance and Economy, Brunei Darussalam (secondary data).

\section{Data Collection}

For this research, primary data are obtained through qualitative surveying (interviews) with the relevant stakeholders that have both direct and indirect contributions towards big data applications in Brunei Darussalam. In addition to that, one-on-one interview was conducted with the aforementioned interviewees where a set of open-ended questions and consent letter were sent prior to the interview session to ensure the interviewees understood the purpose, depth and scope of this research.

With regards to secondary data, it was obtained comprehensively from research papers and systematic review papers (i.e. Google Scholars, ResearchGate, Emerald Insights, ScienceDirect, Wiley Online Library), local newspaper articles (i.e. Media Permata, Borneo Bulletin), local news broadcast (i.e. Radio Television Brunei Darussalam), published government digital reports and press conferences (i.e. Ministry of Health, Ministry of Development, Ministry of Finance and Economy) as well as search engines (i.e. Google, YouTube). These were utilised to search for keywords that comprises of, 'Big Data', 'Big Data Applications', 'Big Data in Public and Private Sectors', 'Digital Era', 'Digital Transformation', 'Big Data in Asia', among others. Articles, systematic reviews, research papers, reports and media files (audio and/or video) in Bahasa Melayu and English languages that revolves around the aforementioned keywords were extensively used to construct the basic understanding and aid in the discussion of this research paper.

\section{Data Analysis}

To analyse the data obtained through the interview sessions, thematic analysis will be used. Thematic analysis method simply refers to the identification of common themes such as relevant topics, ideas and patterns of meanings that comes up repeatedly throughout the multiple interview sessions. Considering the interview are held on a "one-on-one" basis, transcribing of the interviews are necessary in order to analyse the ideas, knowledge and details that are relevant and omit any others that may not be applicable to the objectives of the study. This will then be followed by a process called 'coding' where several important phrases or sentences will be highlighted and labelled. Subsequently, after all the codes have been derived, identification of patterns between the codes will be categorised into different themes. Generally, a theme combines several different but somewhat connected codes into one. Next, themes will be verified to be accurate by comparing the documented themes to the raw transcribed interview. After verification has done the documented themes will be used to achieve the aims of this research paper. 


\section{RESULTS AND DISCUSSIONS}

Multiple digital-based projects have been established by public and private sectors in Brunei Darussalam recently that uses similar key technologies to big data applications such as cloud computing, artificial intelligence, internet of things and fast wireless connectivity. In this research paper, only one apparent big data project that is currently widely used in Brunei Darussalam will be covered, that is BruHealth Application.

An interview session was made with the senior managers of Authority of Information and Technology Industry (AITI) on the current Brunei Darussalam's movement towards big data application (See Appendix A(i)). An interview, dubbed "Uncovered BruHealth", was made public by Idham Abas on 7th September 2020, with the aim to expose the developmental stages, operational aspects as well as the stakeholders involved in building the innovative BruHealth application (Brunei Darussalam's first big data project). The result from primary and secondary data consisting of both qualitative (interviews) and quantitative (annual reports) survey are presented, illustrated and discussed in the following sections.

\section{Social and Environmental Aspect}

In 2019's Human Development Report, Brunei Darussalam is ranked at 43rd out of 189 countries and territories, with reportedly very high human development index of 0.845 , sharing its rank to Hungary (Conceição, 2019). Life expectancy for Bruneian have increased from 75.5 to 75.7 years from 2016 to 2018, showing improvement in the utilisation of local public and private health care system for the betterment of the population health and thus, life expectancy. Moreover, the mean years of school attainment for Brunei Darussalaman adult above 25 years are at 9.1 years and 14.4 years of expected number of school years for children of school-entry age (at least 3 years old). This imperatively shows the population have attained adequate education throughout their lives. Moreover, gross national income (GNI) per capita, that corresponds to the population's purchasing power (purchasing power proprietary - PPP\$) is approximately at PPP $\$ 77,000$ over the last 3 years. This reported GNI over the period of 2016 to 2018 have shown that the Brunei Darussalam government have efficiently redistributed economic benefits that is mainly sourced from oil and gas industry to the public thus, the population have enough purchasing power to acquire life's necessities including technologies in their lives.

South Korea is used as comparison to Brunei Darussalam in the aspect of big data application because it belongs in the Asia regional cluster and has currently deploys big data applications in its public and private sectors such as the mitigation of human epidemic transmissions (i.e. MERS-Cov) in 2014 (Ku, K et al. 2014) and "Owl Project" (SUSA, 2017) respectively. To the knowledge of the authors, currently there are no deployment of big data technologies yet in ASEAN region, thus South Korea is chosen as the best country to compare with Brunei Darussalam. To put things into better perspective, reported recent human development index (HDI) along with for this two countries as being published in Human Development Report 2019 are as illustrated in the following figure.

Brunei Darussalam and South Korea both have very high human development index with scores of 0.845 and 0.906 respectively. Comparing their sub-categories, South Korean's education attainment is

Table 4. Brunei Darussalam HDI 2016 - 2018 adopted from Human Development Report 2019

\begin{tabular}{|l|l|l|l|l|}
\hline & \multicolumn{1}{|c|}{ Life Expectancy } & \multicolumn{1}{|c|}{$\begin{array}{c}\text { Mean Years of } \\
\text { Schooling }\end{array}$} & \multicolumn{1}{|c|}{$\begin{array}{c}\text { GNI per capita } \\
\text { (2011 PPP\$) }\end{array}$} & \multicolumn{1}{|c|}{ HDI Value } \\
\hline 2016 & 75.5 & 9.1 & 77,492 & 0.844 \\
\hline 2017 & 75.6 & 9.1 & 77,188 & 0.843 \\
\hline 2018 & 75.7 & 9.1 & 76,389 & 0.845 \\
\hline
\end{tabular}


approximately three years more than that of Brunei Darussalam's. However, in terms of gross national income per capita, Bruneians enjoy significantly better financial status with approximately PPP\$29k more than South Korea. Thus, with this significantly better financial standing, Brunei Darussalam will have the potential to keep-up with South Korea's progress, given that it improves the quantity and quality of educational attainment, to equip the people with more skillsets and knowledge which aligns with one of core achievement of Brunei Darussalam's Wawasan 2035.

\section{Enabling Environment}

In the aspect of enabling environment, Brunei Darussalam's e-participation shows that only $61 \%$ of the general population uses online services for information sharing i.e. e-government services etc. However, this value is believed to change positively during the recent Covid-19 pandemic because Ministry of Health has imposed a new policy that requires the public to utilise the new self-assessment and contact tracing tool - BruHealth Application - in the nation's effort to contain the virus outbreak in the local community (James Kon, 2020).

On the other hand, South Korea scores $100 \%$ in e-participation, which thus showing the reason why they have successfully implemented and utilise big data technologies in its public and private

Figure 4. HDI Comparison between Brunei Darussalam and South Korea

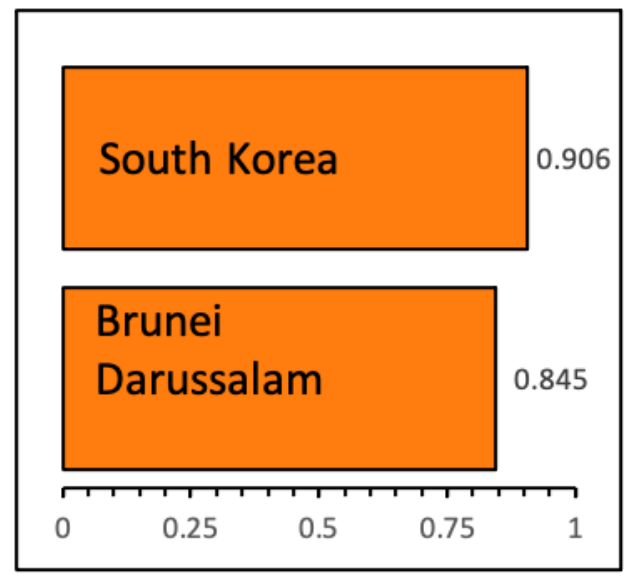

Figure 5. HDI Sub-Categories Comparison

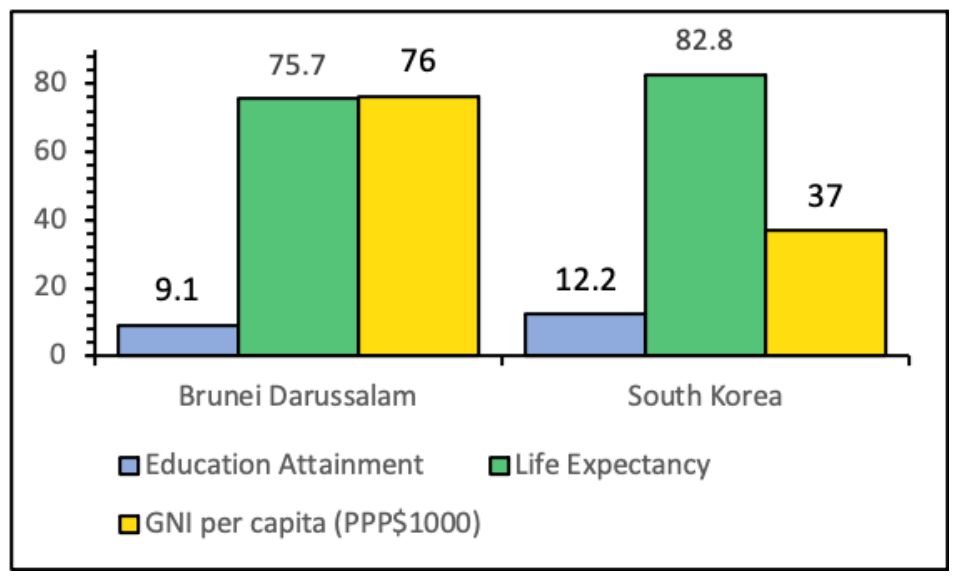


Table 5. Global Competitiveness Index 2019

\begin{tabular}{|c|c|c|c|c|c|}
\hline & Code & Sub-pillar & Legend & Brunei Darussalam & South Korea \\
\hline \multirow{2}{*}{$\begin{array}{l}\text { Enabling } \\
\text { Environment }\end{array}$} & 1.12 & E-Participation & $0-1$ (best) & 0.61 & 1.00 \\
\hline & 1.23 & Government Long-term vision & $1-7$ (best) & 4.90 & 4.40 \\
\hline \multirow{2}{*}{$\begin{array}{l}\text { Human } \\
\text { Capital }\end{array}$} & 6.02 & Extent of staff training & $1-7$ (best) & 4.00 & 4.50 \\
\hline & 6.05 & $\begin{array}{l}\text { Digital skills among active } \\
\text { population }\end{array}$ & $1-7$ (best) & 4.90 & 5.00 \\
\hline Market & 7.03 & Competition in services & $1-7$ (best) & 4.60 & 5.20 \\
\hline \multirow{7}{*}{$\begin{array}{l}\text { Innovation } \\
\text { Ecosystem }\end{array}$} & 11.07 & Growth of innovative companies & $1-7$ (best) & 3.60 & 4.50 \\
\hline & 11.08 & $\begin{array}{l}\text { Companies embracing disruptive } \\
\text { ideas }\end{array}$ & $1-7$ (best) & 3.50 & 4.00 \\
\hline & 12.03 & International co-inventions & per million pop & 1.81 & 14.85 \\
\hline & 12.05 & Scientific publications & score & 63.30 & 578.70 \\
\hline & 12.06 & Patent applications & per million pop & 1.81 & 461.15 \\
\hline & 12.07 & R\&D expenditures & $\%$ GDP & $\mathrm{n} / \mathrm{a}$ & 4.20 \\
\hline & 12.08 & Research institutions prominence & $0-100$ (best) & 0.00 & 0.31 \\
\hline \multicolumn{3}{|c|}{ Overall Global Competitiveness Index } & $\begin{array}{l}\text { Rank } \\
\text { (out of 141) }\end{array}$ & 56th & 13th \\
\hline
\end{tabular}

sectors earlier than Brunei Darussalam. Optimistically, with the wide use of BruHealth Application, it will ease Brunei Darussalam on its transition to use big data technologies for its public and private sectors in the near future.

In addition to that, in the aspect of government long-term vision, Brunei Darussalam scores 4.90 out of 7, which is higher compared to South Korea (4.40). This is a very good sign for Brunei Darussalam, as it shows that its government have the plan to propel the nation's towards greater development. In the recent years, the government of Brunei Darussalam has shown interest towards total digital transformation of its economy and consequently making pathways to advance itself towards the Fourth Industrial Revolution era (Rasidah Abu Bakar, 2019). Parallel to His Majesty's Titah on 21st September 2020 in commemoration to the First National Development Plan Committee Meeting for 2020 below:

Furthermore, in line with the passage of time, I also see that governmental agencies need to strengthen the potential of the Digital Economy through the implementation of the Fourth Industrial Revolution and the Whole of Nation Approach that has already begun to be applied in this country. With the development of several applications such as BruHealth, MOHcares, Smart Users, Transport BN and so on. This is important for us to be able to address the challenges ahead, including as an effort to maintain peace and prosperity.

In its essence, His Majesty hopes that Brunei Darussalam's governmental agencies should play their significant roles in ensuring the success of digital economy transformation by utilising the Whole of Nation approach in the nation's advancements towards the fourth industrial revolution. One of the apparent initiatives made towards this macro-level transformation is the making of Digital Economy Masterplan 2025 with the aim to outline strategies towards Smart Nation which comprises of digital and future-ready society with sustainable economy and conducive digital ecosystem (The Scoop, 2020). In addition to that, Wawasan 2035 which is Brunei Darussalam's aspiration and vision to become a nation with highly educated, skilled and accomplished citizens with high quality of 
life backed up with dynamic and sustainable economy (Wawasan 2035, 2019). These new notions have imperatively proved that Brunei Darussalam's government do have long-term plan to raise its competitiveness and welfares in the years to come.

\section{Human Capital}

Brunei Darussalam scores 4 out of 7 in the aspect of extent of staff training. This corresponds to the investments in trainings and development for employees by companies. Re-training of staffs are needed especially during Brunei Darussalam's verge of transformation towards digital economy. Neglecting staff trainings would cause more harm towards the labour forces as a whole, as it would cause harder transitions towards further transformation in the years to come due to their incompetency to do work. Moreover, digital skills among active population is significantly high, showing that Brunei Darussalam's general population have adequate digital literacy to adopt smart devices and innovative technologies.

\section{Market}

Based on the report, Brunei Darussalam scores 4.6 out of 7 for competition in services, showing that there is only enough competitions between the local private sectors, considerably smaller than that of South Korea (5.2 out of 7) inherently showing South Korea has higher competitivity within their society. This level of competitivity in Brunei Darussalam is agreed upon by a Senior Manager in Corporate Strategy of AITI, who commented as below:

Here (Brunei Darussalam) would be a non-competitive zone. Because not much of fighting (competition) happen between businesses to grab their part. ...So basically, we (Bruneians) are not hungry. When you are hungry, you want to compete. And you try to think of the edge that you should have to compete against others.

Level of competitivity between businesses is essential to induce the extent of innovativeness of the nation. In this context, it shows the level of competitiveness within the professional services, retail services and network sectors in Brunei Darussalam should be more competitive to ensure more innovations in the upcoming years.

\section{Innovation Ecosystem}

In conjunction to the Brunei Darussalam's market competitivity being stated in the previous section, it may make sense that growth of innovative companies (in Innovation Ecosystem Pillar) in Brunei Darussalam is at 3.6 out of 7, relatively the lowest compared to South Korea (4.50) and Japan (4.60). Another reason for this lack of growth is the fact that some companies are not ready to embrace new technologies that would disrupt their current business model. For instance, as part of the solution towards better household garbage management, AITI has proposed a new project that revolves around a data-driven rubbish services by utilising IoT and cloud services. This was addressed by the Senior Executive of Resource Management in AITI, who commented on it as below:

When we have that idea (to make an data-driven garbage management services), there are a lot of challenges. Because it would disrupt the current garbage business models. So, the question is do we have to change our (business) model? Because if they don't alter their operations, they would just gather the data saying it's full and don't react to it, there's no point.

Based on this statement, it can be observed that he may be quite worried of the reluctancy of local businesses (in this context, garbage collectors) to transform their business models from a traditional model to a data-driven business model. The level of reluctancy can be measured from companies 
embracing disruptive ideas sub-pillar of Innovation Ecosystem. Brunei Darussalam is scored at 3.50 out of 7, thus showing arguably most of the existing local companies are not willing adopt disruptive technologies into their business practices. This case is different from South Korea that scores 4 out of 7 and Japan that scores 3.90 out of 7 which relatively higher than of Brunei Darussalam's. Finally, in comparison to South Korea, Brunei Darussalam scores relatively the lowest in terms of international co-inventions, scientific publications and patent applications. In the years to come, if Brunei Darussalam wishes to advance further in inventing new disruptive technologies, it would be best that Brunei Darussalam participates heavily in these sub-pillars to widen the horizons of knowledge on digital technology industry.

\section{TECHNOLOGY ASPECT}

\section{Cloud Computing and Artificial Intelligence}

In response to Covid-19 pandemic, the Ministry of Health (MOH) with with Ministry of Finance and Economic (MOFE) in collaboration with Evyd Technology Sdn. Bhd. (a franchise of Yidu Cloud) have developed BruHealth mobile application in the effort to contain the contagious virus outbreak in Brunei Darussalam. This application acts as the main tool for $\mathrm{MOH}$ to mainly assess the logs of places that the infected individual(s) have been to before and after he/she was positively infected (e.g. mosques, restaurants, shops). Consequently, contact tracings of other individuals in close proximity to the infected individual(s) at the exact time, date and places can be pinpointed, thus helping $\mathrm{MOH}$ make strategically better screening test for these suspected individuals.

Regarding the operational aspect of BruHealth App, Minister at $\mathrm{MOH}$ has responded as such:

... a system where the public have correct information and correct data to be shared as well and where they can make inquiries as well using the system. We want people to know where these infections or the person who have been infected as well and what are the potential risks they could have amongst the public.

Minister at MOFE has also added as such:

So, with this app, we allowed them (public) to monitor not just the situation in the country but also globally. I believe this will be a good platform for us to put all the information to one.

Based on the two statements above, it can be observed that BruHealth application acts as a single application that collects vast amount of data shared by the public to make the BruHealth system more reliable. Data collected from BruHealth application itself is very large because it constantly collects users' health data (whole Brunei's population) and logged their GPS locations every seconds of the day.

In ensuring the success of data collection, the theory of exchange is involved, where the public is offered imminent information on current Covid-19 situation (i.e. code Green, Yellow, Red), whereas in return, the government requires full involvement by public towards the application. Inherently, this improves the transparency between the societal public with the government, thus ensuring the trust between them is strongly forged.

In the aspect of BruHealth app development, Minister at MOFE has responded as such:

...through MOFE contact, we managed to talk to this company called Yidu Cloud. It is actually an industry leading medical AI technology company that provides innovative medical solutions using data intelligence. 
Moreover, in the context of the location of BruHealth data base, Minister at MOFE has responded as such:

...the servers are in the country.

Based on the statement above, this application is outsourced by MOFE from Yidu Cloud (a Chinabased company). This company is an industry leading medical artificial intelligence company that provides innovative medical solutions using big data technologies. This crucially becomes a memento of collaboration between the public sectors (Brunei government) with a private sector (Yidu Cloud) to implement big data application for the benefit of the public's welfare.

Minister at MOFE and MOH proposed to use artificial intelligence (AI) because it will significantly help the government in dictating any decisions and responses that are crucial to be strategically executed with minimal errors during this time of pandemic. Moreover, the application uses cloud computing system (inherent feature of web 2.0 infrastructure), thus requires the existence of local database servers that acts as the "bucket" for data collection. In addition to that, in the aspect of data security assurance in BruHealth app, Minister at MOFE has stated as below:

So, to ensure that there is no misuse ... we brought in the virus government agencies into this team. So, we also make sure that this system is as fool proof as possible, equipped with things like web application protection, intrusion detection system and so on.

Based on this statement, it imperatively shown that the BruHealth database contain both public and confidential information that has limited access for any of its users. Although not specified, the cloud computing infrastructure is believed to be a hybrid cloud - a mixture of public and private cloud - with Software as a Service (SaaS) deliverability, because only the governmental authorities (Ministry of Health) have the right to dictate the types of information that can be shared to the public and the other types of information that are only available to specific entities via MOH's intranet. Thus, with these statements at hand, we can conclude that the first two key technologies i.e. cloud computing and artificial intelligence, have already been acquired and successfully utilised by the Brunei Darussalam's government.

\section{Internet of Things and Network Connectivity}

Another key technology for the successful implementation of big data technology is the widespread use of two co-existing technologies: interconnected smart devices (IoT) to the wireless network connections (i.e. WIFI, mobile broadband, NFC, etc). A recent survey report was conducted by Brunei Computer Emergency Response Team (BruCERT, 2020) between 17 to 23 April 2020, collecting responses from 3000 individuals to apprehend the home-based studying or working experiences faced by the respondents during this Covid-19 pandemic in Brunei Darussalam.

Table 6. Devices Used by Brunei Population during Covid-19 Pandemic reported by BruCERT (2020)

\begin{tabular}{|l|l|l|}
\hline \multicolumn{1}{|c|}{ Available Devices } & \multicolumn{1}{c|}{ Responses } & \multicolumn{1}{c|}{ No. of Respondents } \\
\hline Laptop & $83.30 \%$ & 2,499 \\
\hline Desktop Computer & $16.70 \%$ & 501 \\
\hline Tablet & $16.00 \%$ & 480 \\
\hline Mobile Phone & $74.07 \%$ & 2,222 \\
\hline Others & $1.47 \%$ & 44 \\
\hline
\end{tabular}


Based on table above, it has shown that $83.30 \%$ of respondents has laptop, $16.7 \%$ has desktop computers, $16 \%$ has tablets and $74.07 \%$ has mobile phones. All devices reported in this survey have the capability to connect to the internet and able to compute complex functionality, thus satisfies the main feature of "smart" devices. This inherently shown that the Bruneian population in general has enough purchasing power to acquire electronic devices to fulfil their work necessities and for daily usage.

As above, Brunei Darussalam's reported score of internet users is $94.6 \%$. This inherently shows that Brunei has significant internet penetration in the recent years as the result of the widely available wireless internet (WIFI) connectivity as well as the vast coverage of mobile network connections that can be found at every home, schools, buildings etc. The acquirement of smart electronic devices and subscriptions to internet and mobile broadbands made sense as the Brunei population has enough disposable income which can be verified from the relatively high purchasing power propriety that was reported in the Global Competitive Report 2019.

As above, it has shown that $24.93 \%$ of respondents (748) spent more than 10 hours connected to the internet where the largest portion of respondents (34.4\% or 1,032 respondents) are connected to the internet at 5 to 7 hours per day. This imperatively shown that Brunei population in general are constantly connected to the internet, thus becomes an opportunity for governmental agencies to monitor, understand and capitalise the virtual behaviours of Bruneians more precisely. The usability of such smart devices (especially smart phones) by the Brunei's general public becomes apparent during this Covid-19 pandemic. As part of the current policy imposed by Brunei government through Ministry of Health, individuals that wish to access public premises are required to scan QR codes as well as enable mobile internet and Bluetooth connectivity.

Unified National Network (UNN) is a governmental organisation that oversees the four main telecommunications service providers in Brunei Darussalam which consisted of Imagine Sdn Bhd (imagine), Datastream Technology Sdn Bhd (DST), Progresif Cellular Sdn Bhd (Progresif) and Brunei International Gateway Sdn Bhd (BIG). In the midst of the popular notion of the next generation network connectivity, UNN with Ministry of Transport and Info-communication (MTIC) and Authority for Info-communications Technology Industry (AITI) have made collaborations to

Table 7. Internet Subscription reported in Global Competitive Report 2019

\begin{tabular}{|l|l|l|l|}
\hline \multicolumn{1}{|c|}{ Code } & \multicolumn{1}{|c|}{ Sub-pillar } & \multicolumn{1}{c|}{ Legend } & \multicolumn{1}{c|}{ Brunei Darussalam } \\
\hline 3.01 & Mobile-cellular telephone subscription & per 100 pop & 131.90 \\
\hline 3.02 & Mobile-broadband subscription & per 100 pop & 130.00 \\
\hline 3.03 & Fixed-broadband subscriptions & per 100 pop & 11.90 \\
\hline 3.04 & Fibre internet subscriptions & per 100 pop. & 6.30 \\
\hline 3.05 & Internet users & $\%$ of adult pop. & 94.60 \\
\hline
\end{tabular}

Table 8. Internet Usage by Brunei Population during Covid-19 Pandemic reported by BruCERT (2020)

\begin{tabular}{|l|l|l|}
\hline \multicolumn{1}{|c|}{ Online Usage per day } & \multicolumn{1}{|c|}{ Responses } & No. of Respondents \\
\hline More than 10 hours & $24.93 \%$ & 748 \\
\hline 8 to 10 hours & 27.33 & 820 \\
\hline 5 to 7 hours & $34.40 \%$ & 1,032 \\
\hline Less than 4 hours & $13.33 \%$ & 400 \\
\hline Total & $100 \%$ & 3000 \\
\hline
\end{tabular}


evaluate and carve pathways for the implementation of $5 \mathrm{G}$ network technologies to replace the current $4 \mathrm{G}+$ and LTE network.

This adoption of new network connectivity would be the stepping stone for Brunei's Digital Economy Masterplan 2025 towards Smart Nation, as being stated by the Senior Executive of Resource Management, AITI below:

One of the enabling parts is connectivity. So AITI as a regulator, we are responsible to ensure in terms of connectivity. In the Digital Economy Masterplan 2025, 5G is one of the enabling technologies.

The connectivity between multiple smart devices with one another and the relatively fast data transmission to BruHealth's cloud servers have crucially warrants the success of big data application in Brunei Darussalam.

\section{Policy Factor}

Finally, the last key enabler to implementation to big data application in Brunei Darussalam is the presence of data privacy policy. Establishment of data privacy policy will ensure the public society in general is informed of the security of their privacy as well as to validate the purposes of the multidimensional types of data collected from them.

Moreover, the society will have utmost confidence to voluntarily participate in any data collecting initiatives which will be very crucial to fulfil the volume and thus value aspect of big data applications. In general, data privacy policy will inherently build utmost trust and transparency between the data collecting entities from private and public sectors with the general society.

As in the case of Brunei Darussalam, data privacy policy's existence and its significance has been addressed by the Senior Executive in Resource Management of AITI as stated below:

So, Brunei is one of those countries that haven't had a national law on data protection. Brunei is still actively enacting a law on data protection. The (data privacy) law is already in the making. This is to ensure people have the confidence in terms of data usability.

Consequently, data privacy and security was also being addressed by the Minister at Ministry of Finance and Economy, after he was being pointed out the public's (Bruneians) concerns on sharing their personal data on BruHealth Application, as quoted below:

...we want to ensure the public that there is no intention for the Government to try to take advantage of the data that we have collected from people scanning in and out ... We brought in ITPSS and EGNC to ensure that the servers are in the country ... also make sure that this system is as fool proof as possible equipped with things like web application protection, intrusion detection system and so on. So that it it not subjected to cyber-attacks and so on.

And again, just as I said, just want to re-emphasise again, we have no intention to use it for other purposes.

Clearly, as being mentioned above, it has shown that the Brunei's government emphasises on the usability of BruHealth applications (big data application) by exposing their approach on the security protection and user's rights to their data. Although national law on data protection and data privacy policy has not being established for the public, there is an evidence of the existence of Data Protection Policy that protects Brunei Government's electronic data and paper records that oversees the people that uses them, the processes they follow and the physical equipment that were used to access them 
(Rahaman, 2015). Brunei Darussalam in the upcoming years will see the establishments of Digital Data Policy that governs the utilisation of data across the nation's public and private sectors.

\section{CONCLUSION}

In conclusion, nation's readiness towards implementation of any new disruptive technologies shall be assessed based on its Social, Technological, Environmental and Policy aspects (STEP). Brunei Darussalam is one of developing countries in ASEAN region, that to our knowledge, satisfies three out of four key requirements for successful adoption of big data technologies (i.e. Social, Technological and Environmental). The evident success of public sector's objective to contain the Covid-19 community spread through BruHealth Application (its first big data project) has shown that Brunei has the utmost potential to further capitalise this technology for the nation's private sectors. Successful adaptation of this cutting-edge technologies would imminently, in researcher's point of view, solve the prominent unemployment issue. However, the aforementioned statement is too soon to be concluded, thus an opportunity to research on the integration of human resource management and big data technologies shall be conducted in the near future. 


\section{REFERENCES}

Aheleroff, S., Xu, X., Lu, Y., Aristizabal, M., Pablo Velásquez, J., Joa, B., \& Valencia, Y. (2020). IoT-enabled smart appliances under industry 4.0: A case study. Advanced Engineering Informatics, 43(December), 101043. 10.1016/j.aei.2020.101043

Anderson, S., \& Blanke, T. (2012). Taking the long view: From e-science humanities to humanities digital ecosystems. Historische Sozialforschung, 147-164.

Asghari, P., Rahmani, A. M., \& Javadi, H. H. S. (2019). Internet of Things applications: A systematic review. Computer Networks, 148, 241-261. doi:10.1016/j.comnet.2018.12.008

Bandial \& Bakar. (2019). Hengyi refinery to be operational by end of 2019. Retrieved on 11th September 2020, From https://thescoop.co/2019/03/01/hengyi-refinery-to-be-operational-by-end-of-2019/

Bello, O., \& Zeadally, S. (2019). Toward efficient smartification of the Internet of Things (IoT) services. Future Generation Computer Systems, 92, 663-673. doi:10.1016/j.future.2017.09.083

Borneo Project. (2014). Introduction to Borneo. Retrieved on 21st September 2020, Retrieved From https:// borneoproject.org/borneo-2/

Chan, B. S. K., Churchill, D., \& Chiu, T. K. F. (2017). Digital literacy learning in higher education through digital storytelling approach. Journal of International Education Research, 13(1), 1-16. doi:10.19030/jier.v13i1.9907

Chang, V. (2018). A proposed social network analysis platform for big data analytics. Technological Forecasting and Social Change, 130(November), 57-68. 10.1016/j.techfore.2017.11.002

Conceição, P. (2019). Human Development Report 2019. United Nations Development Program.

Demirkan, H., \& Delen, D. (2013). Leveraging the capabilities of service-oriented decision support systems: Putting analytics and big data in cloud. Decision Support Systems, 55(1), 412-421. doi:10.1016/j.dss.2012.05.048

DEPS. (2019). Report of the Mid-Year Population Estimates 2019. Author.

Dube, S., \& Danescu, D. (2011). Supplemental guidance: Public sector definition. The Institute of Internal Auditors-Global, Altamonte Springs.

Duch-Brown, Nn., Martens, B., \& Mueller-Langer, F. (2017). The Economics of Ownership, Access and Trade in Digital Data. SSRN Electronic Journal. 10.2139/ssrn.2914144

Durao, F., Carvalho, J. F. S., Fonseka, A., \& Garcia, V. C. (2014). A systematic review on cloud computing. The Journal of Supercomputing, 68(3), 1321-1346. doi:10.1007/s11227-014-1089-x

Fortino, G., Russo, W., Savaglio, C., Viroli, M., \& Zhou, M. (2017). Modeling Opportunistic IoT Services in Open IoT Ecosystems. WOA, 90-95.

Gaitanou, P., Garoufallou, E., \& Balatsoukas, P. (2014). The effectiveness of big data in health care: A systematic review. Communications in Computer and Information Science, 478, 141-153. doi:10.1007/978-3-319-136745_14

Galetsi, P., Katsaliaki, K., \& Kumar, S. (2019). Values, challenges and future directions of big data analytics in healthcare: A systematic review. Social Science \& Medicine, 241(February), 112533. doi:10.1016/j. socscimed.2019.112533 PMID:31585681

Griffin, R. (2012). Using Big Data to combat enterprise fraud: To combat fraud, more organizations are thinking big-employing new approaches around Big Data to convert the volumes of information available into useful insight and real action. Financial Executive, 28(10), 44-48.

Gubbi, J., Buyya, R., Marusic, S., \& Palaniswami, M. (2013). Internet of Things (IoT): A vision, architectural elements, and future directions. Future Generation Computer Systems, 29(7), 1645-1660. doi:10.1016/j. future.2013.01.010

Gunness, S., \& Singh, U. G. (2015). Integrating Learning Analytics for higher-order thinking e-assessments. 2015 International Conference on Computing, Communication and Security (ICCCS), 1-8. doi:10.1109/ CCCS.2015.7374143 
Khurpade, J. M., Rao, D., \& Sanghavi, P. D. (2018). A Survey on IOT and 5G Network. 2018 International Conference on Smart City and Emerging Technology (ICSCET), 1-3. doi:10.1109/ICSCET.2018.8537340

Kim, G.-H., Trimi, S., \& Chung, J.-H. (2014). Big-data applications in the government sector. Communications of the ACM, 57(3), 78-85. doi:10.1145/2500873

Kim, T., Ramos, C., \& Mohammed, S. (2017). Smart city and IoT. Elsevier. doi:10.1016/j.future.2017.03.034

Kim, Y. H., \& Ahn, J. H. (2016). A Study on the Application of Big Data to the Korean College Education System. Procedia Computer Science, 91, 855-861. 10.1016/j.procs.2016.07.096

Marston, S., Li, Z., Bandyopadhyay, S., Zhang, J., \& Ghalsasi, A. (2011). Cloud computing - The business perspective. Decision Support Systems, 51(1), 176-189. doi:10.1016/j.dss.2010.12.006

Mistry, I., Tanwar, S., Tyagi, S., \& Kumar, N. (2020). Blockchain for 5G-enabled IoT for industrial automation: A systematic review, solutions, and challenges. Mechanical Systems and Signal Processing, 135, 106382. doi:10.1016/j.ymssp.2019.106382

Muralidharan, S., Roy, A., \& Saxena, N. (2018). MDP-IoT: MDP based interest forwarding for heterogeneous traffic in IoT-NDN environment. Future Generation Computer Systems, 79, 892-908. doi:10.1016/j. future.2017.08.058

Nelson, B., \& Olovsson, T. (2016). Security and privacy for big data: A systematic literature review. 2016 IEEE International Conference on Big Data (Big Data), 3693-3702. doi:10.1109/BigData.2016.7841037

Ohata, M., \& Kumar, A. (2012). Big data: A boon to business intelligence. Financial Executive, 28(7), 63-65.

Othman. (2020). Brunei 44th most innovative among high income economies. Retrieved on 21st September 2020, Retrieved from https://borneobulletin.com.bn/2020/09/brunei-44th-most-innovative-among-high-incomeeconomies-2/

Pervez, S., Abosaq, N. H., \& Alandjani, G. (2018). Internet of Things (IoT) beginning for Jail-Less Community in Smart Society Internet of Things (IoT) beginning for Jail-Less Community in Smart Society. Academic Press.

Peterson, A. (2018). Big Data in Education: New Efficiencies for Recruitment, Learning, and Retention of Students and Donors. In Handbook of Statistical Analysis and Data Mining Applications (2nd ed.). Elsevier Inc. doi:10.1016/B978-0-12-416632-5.00013-X

Porter, M. E., \& Gibbs, M. (2001). Strategy and the Internet. Academic Press.

Putterman, L. (2013). Institutions, social capability, and economic growth. Economic Systems, 37(3), 345-353. doi:10.1016/j.ecosys.2012.12.002

Rahaman, P. (2015). Data Protection Policy. E-Government National Centre, 2015, 1-4.

Raja, R., Mukherjee, I., \& Sarkar, B. K. (2020). A Systematic Review of Healthcare Big Data. Scientific Programming, 2020, 1-15. doi:10.1155/2020/5471849

Rajagopalan, M. R., \& Vellaipandiyan, S. (2013). Big data framework for national e-governance plan. 2013 Eleventh International Conference on ICT and Knowledge Engineering, 1-5. doi:10.1109/ICTKE.2013.6756283

Reddy, P., Sharma, B., \& Chaudhary, K. (2020). Digital literacy: A review of literature. International Journal of Technoethics, 11(2), 65-94. doi:10.4018/IJT.20200701.oa1

Saxby, S., \& Knight, A. (2013). Identity crisis: Global challenges of identity protection in a networked world. Academic Press.

Shah, S. H., \& Yaqoob, I. (2016). A survey: Internet of Things (IOT) technologies, applications and challenges. 2016 IEEE Smart Energy Grid Engineering (SEGE), 381-385.

Souri, A., Hussien, A., Hoseyninezhad, M., \& Norouzi, M. (2019). A systematic review of IoT communication strategies for an efficient smart environment. Transactions on Emerging Telecommunications Technologies, (May), 1-19. doi:10.1002/ett.3736

Spires, H. A., \& Bartlett, M. E. (2012). Digital literacies and learning: Designing a path forward. Friday Institute White Paper Series. 
Spires, H. A., Paul, C. M., \& Kerkhoff, S. N. (2019). Digital literacy for the 21st century. In Advanced Methodologies and Technologies in Library Science, Information Management, and Scholarly Inquiry (pp. 12-21). IGI Global.

Stocker, M., Baffes, J., Some, Y. M., Vorisek, D., \& Wheeler, C. M. (2018). The 2014-16 oil price collapse in retrospect: sources and implications. The World Bank. doi:10.1596/1813-9450-8419

Swedberg, R. (2018). On the Uses of Exploratory Research and Exploratory Studies in Social Science. Academic Press.

Tankard, C. (2012). Big data security. Network Security, 2012(7), 5-8. doi:10.1016/S1353-4858(12)70063-6

Terroso-Saenz, F., González-Vidal, A., Ramallo-González, A. P., \& Skarmeta, A. F. (2019). An open IoT platform for the management and analysis of energy data. Future Generation Computer Systems, 92, 1066-1079. doi:10.1016/j.future.2017.08.046

Thompson, A., Peteraf, M., Gamble, J., Strickland, A. J. III, \& Jain, A. K. (2013). Crafting \& executing strategy 19/e: The quest for competitive advantage: Concepts and cases. McGraw-Hill Education.

Wamba, S. F., Akter, S., Edwards, A., Chopin, G., \& Gnanzou, D. (2015). How 'big data'can make big impact: Findings from a systematic review and a longitudinal case study. International Journal of Production Economics, 165, 234-246. doi:10.1016/j.ijpe.2014.12.031

White, M. (2012). Digital workplaces: Vision and reality. Business Information Review, 29(4), $205-214$. doi:10.1177/0266382112470412 